\title{
Myelodysplastic Syndrome and Colon Cancer Relationship: A Case Report
}

\author{
Asmaa El Hussainy*, Asit Mohanty and Jasem Al Barrak \\ Department of medical oncology, KCCC, Kuwait
}

Submission: August 31, 2020; Published: September 15, 2020

*Corresponding author: Asmaa El Hussainy, Department of medical oncology, KCCC, Kuwait

Abstract

Background: The use of alkylating agent and antimetabolite is associated with the development of therapy related acute leukemia or myelodysplastic syndrome. MDS may also occur as a separate entity in Patients of CRC who are treated with chemotherapy. The average time until onset of tMDS depends on the type and amount of chemotherapy used and varies from 2 to 7 years. We are presenting a case that had MDS shortly after treatment of CRC with Adjuvant Chemotherapy which is not a common entity.

Case presentation: A 66 years old man was diagnosed as a case of colon cancer treated by surgery followed by chemotherapy for 6 months. Myelodysplastic syndrome was diagnosed due to persistent anemia post chemotherapy. He is under follow up with GIT unit for colon cancer and hematology unit for treatment of myelodysplastic syndrome.

Conclusion: This article to emphasize that is there a possibility of etiologic correlation between colon cancer chemotherapy treatment and myelodysplastic syndrome.

Keywords: Colon cancer; MDS; Chemotherapy; Second neoplasm

\section{Introduction}

Colorectal cancer is considered as a common disease worldwide. Historically Treatment modalities have included surgery, 5- fluorouracil (5-FU) and /or radiation. Over the past ten years standard treatment has evolved and now includes platinum compounds such as oxaliplatin, topoisomerase I inhibitors (irinotecan) and oral analogue of 5-FU (capacitabine) [1]. Secondary neoplasm may occur in patients with colon cancer following chemotherapy as a complication or as a separate entity. The use of alkylating agent and antimetabolite is associated with the development of therapy related acute leukemia or myelodysplastic syndrome [2-4]. Myelodysplastic syndrome is a bone marrow failure in which differentiation and maturity do not happen naturally and dysplasia exists in each of the 3 cell categories in bone marrow. Myelodysplastic syndrome may be primary or secondary. Chemotherapy is one of the most important reasons for secondary MDS [5].

\section{Case presentation}

Male patient 66 years old with past medical history of malarial infection 2001, pulmonary tuberculosis 2003 and inflammatory bowel disease (UC) on treatment. In July 2006 was diagnosed as a case of cancer rectum (stage I) he underwent
Trans anal local resection. Histopathological analysis showed tubulovillous adenoma with focus of well differentiated adenocarcinoma infiltrating muscularis mucosa (T1 N0 M0). Patient kept under regular follow up. In August 2016, He suffered from lower abdominal pain, bloating and bleeding per rectum with iron deficiency anemia. Colonoscopy revealed mass in sigmoid colon obstructing the lumen, and biopsy showed invasive adenocarcinoma. CT scan CAP showed no distant metastasis, CEA $=15.2 \mathrm{ng} / \mathrm{ml}$. He underwent laparoscopic resection of colonic lesion with colorectal anastomosis histopathology was invasive adenocarcinoma moderate differentiation (Duck's C) (T2N2b M0), Stage III. He received adjuvant chemotherapy CAPOX protocol for 6 months (11/2016-5/2017) that was complicated by myelosuppression requiring repeated blood transfusion with growth factor and chemo dose adjustment. Follow-up CT scan CAP in May 2017 showed no evidence of local recurrence or distant metastasis. But still patient was suffering from anemia (Figure 1).

He was referred to hematology clinic in June 2017 due to persistent symptomatic anemia post chemotherapy. He has no bleeding orifices, eating well no vomiting or diarrhea. His bone marrow examination showed hyper cellular marrow with evidence of erythroid dysplasia and significant ringed sideroblast 


\section{Cancer Therapy \& Oncology International Journal}

$70 \%$ and blast $8 \%$. Bone marrow conventional cytogenetics (46 XY) FISH for 5 \& 7 were negative. Based on clinical data patient was diagnosed as a case of myelodysplastic syndrome (refractory anemia with excess blast- RAEB II), international prognostic scoring system (IPSS) low risk. So, he kept under care of hematologist for treatment of his myelodysplastic disorders with multiple lines of treatment includes erythropoietin injection, hypomethylation agent (azacitidine), and stem cell transplant. Regarding his colon cancer kept under regular follow up. Last assessment was August 2019 was negative for local recurrence or metastatic disease (Figures $2 \& 3$ ).

Figure 1: Showing no metastasis.
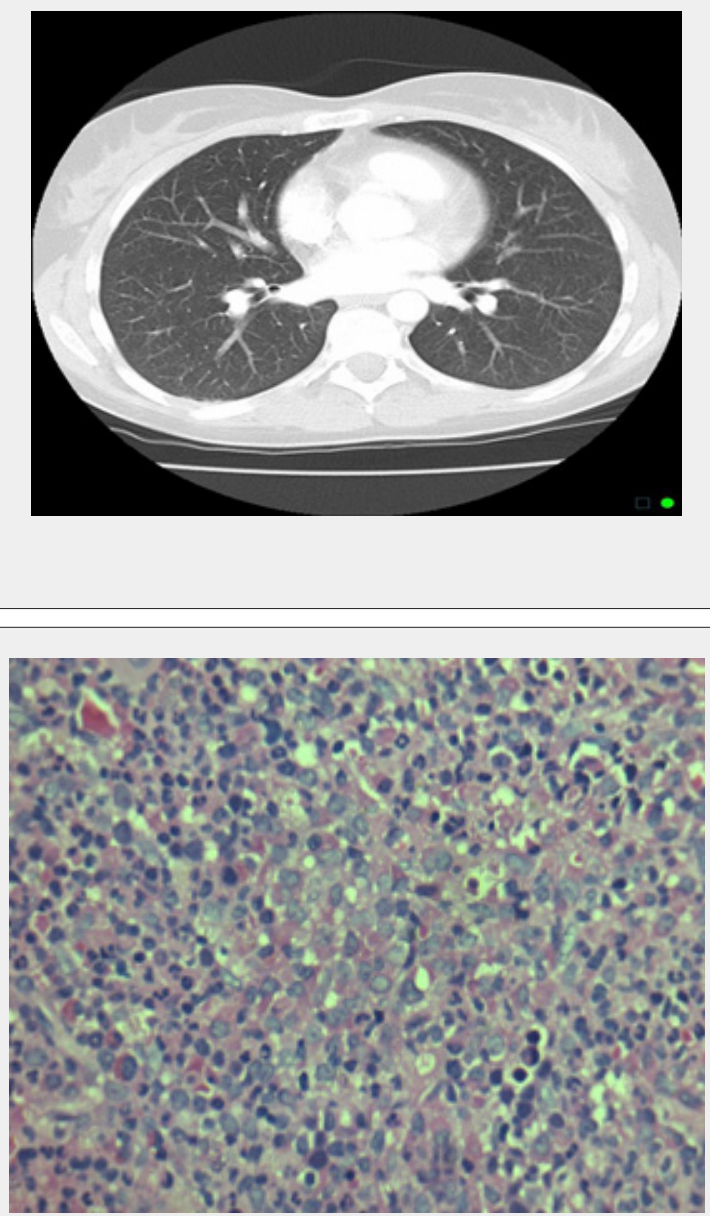

Figure 2: Bone Marrow Biopsy Picture.

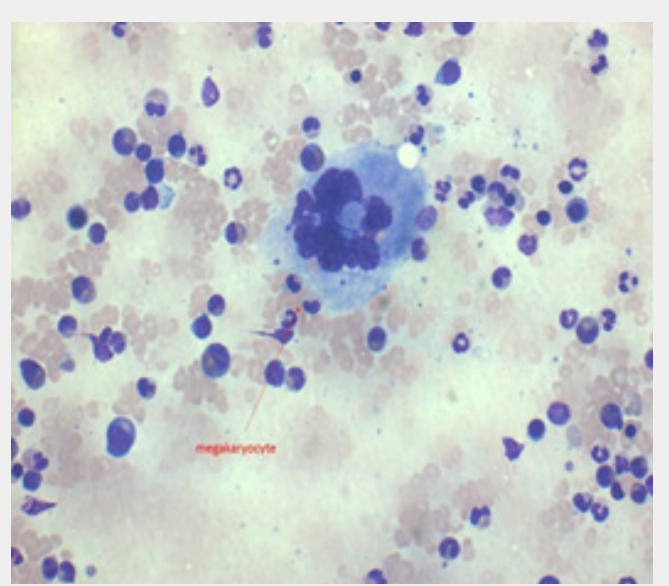

Figure 3: Bone Marrow Biopsy Picture. 


\section{Cancer Therapy \& Oncology International Journal}

\section{Discussion}

The incidence of therapy related MDS /AML were less than $1 \%$ at 10 years after chemotherapy for most solid tumors. However, prognosis following therapy related MDS/AML diagnosis was poor [6]. Because therapy related MDS/AML is rare, most data on the disease have come from case series, case control studies, and clinical trials, which often include a relatively small number of therapy- related MDS/AML. The occurrence of acute leukemia or MDS after diagnosis of colorectal cancer has never been systemically investigated in a large clinical trial. Our case study getting support depending on results obtained from study done at Memorial Sloan- Kettering Cancer Center where the patients with colon cancer, rectal cancer and anal cancer were subsequently diagnosed with acute leukemia or MDS post their treatment.

The risk of developing t-MDS is likely to be a complex interaction of the chemotherapeutic agents, dosages, radiation intensity, genetic factors, environment, comorbidities, and age of the patient. Although any cytotoxic agent can increase the risk of t-MDS, alkylating agents and topoisomerase II inhibitors are especially causative. Alkylating agents covalently modify the DNA, causing DNA cross-linking, double-stranded breaks, mutations, and cytotoxicity. The cumulative dosage correlates with the incidence of t-MDS, and some alkylating agents are more leukemogenic than others Alkylating agents are associated with longer latency to t-MDS, a presentation of MDS often progressing to AML, deletions of chromosome 5 , loss or deletion of chromosome 7 , and a poor prognosis. Platinum-based chemotherapeutic agents have a weaker association with t-MDS.

Topoisomerase-II inhibitors induce double-stranded DNA breaks by preventing relegation of the DNA strands cleaved by the enzyme to facilitate unwinding of the DNA during replication and are correspondingly linked with balanced translocations. The average time until onset of tMDS depends on the type and amount of chemotherapy used. For alkylating agents and topoisomerase inhibitors the average time until onset of tMDS is 5 to 7 years and 2 to 3 years, respectively. Different chemotherapy agents are associated with different genetic mutations; alkylating agents being associated with rearrangements in chromosome 5 and/ or 7 [6]. Our patient presumably developed tMDS 6 month after his treatment with Capacitabine and Oxaliplatin which is quite unusual. TMDS is traditionally associated with alkylating agents and topoisomerase inhibitors. However, cases of 5FU derived tMDS have also been reported [7-9].

\section{Conclusion}

Of note, therapy related myelodysplasia is common with alkylating agent and platinum-based chemotherapy and in need to be under proper follow up as it is pre leukemia state. The massage from our case study is that, while advances in cancer treatment approaches have improved the prognosis for many types of cancer, the number of patients at risk of developing rare therapyrelated MDS/AML after treatment with the modern treatment era has markedly expanded. Though it is reported in literatures that therapy related MDS occur years after chemotherapy, it can happen after short duration also. Future studies of larger databases of patients may help establish if acute leukemia or MDS seen after colon cancer are related to prior exposure to anticancer therapy or there is etiological relation.

\section{References}

1. Eytan M Stein, Vipul Pareek, David Kudlowitz, Dan Douer, Martin S Tallman (2012) acute leukemia following a diagnosis of colorectal cancer : are they therapy related ? Blood 120: 1453.

2. Rubin CM, Arthur DC, Woods WG, Lange BJ, Nowell PC, et al. (1991) therapy related myelodysplastic syndrome and acute myeloid leukemia in children: correlation between chromosomal abnormalties and prior therapy. blood 78: 2982-2988.

3. Leone G, Mele L, Pulsoni A, Equitanti F, Pagano L (1999) the incidence of secondary leukemia. Hematologica 84: 937-945.

4. Takeyama K, Seto M, Uike N, InoT, Mikuni C, et al. (2000) therapyrelated leukemia and meyldysplastic syndrome : a large- scale Japanese study of clinical and cytogenetics features as well as prognostic factors. Int J Hematol 71(2): 144-152.

5. Mozaffar Aznab, Kaveh Kavianymoghadam (2013) secondary myelodysplastic syndrome may happen same as paraneoplastic syndrome ina period of time and prior to the appearance of malignancy. Int J Hematol Oncol Stem Cell Res 7(2): 30-34.

6. Lindsay Morton, Graca M, Dores, Sara J Schonfeldel, Martha S Lin, Byron S Sigel, et al. (2019) association of chemotherapy for solid tumors with development of therapy related myelodysplastic syndrome or acute myeloid leukemia in the modern era. JAMA oncol 5(3): 318-325.

7. Levine EQ, Bloomfield CD (1992) Leukemia and myelodysplastic syndromes secondary to drug, radiation, and environmental exposure. Semin Oncol 19(1): 47-84.

8. Nowell PC (1992) chromosome abnormalities in meylodysolastic syndrome. Semin Oncol 19(1): 25-33.

9. Park HJ, Choi JH, Lee KA, Kim HC, Nam YS, et al. (2012) A case of therapyrelated acute myeloid leukemia following 5fluorouracil chemotherapy. Korean J Intern Med 27(1): 115117. 


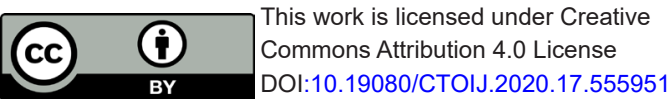

Your next submission with Juniper Publishers will reach you the below assets

- Quality Editorial service

- Swift Peer Review

- Reprints availability

- E-prints Service

- Manuscript Podcast for convenient understanding

- Global attainment for your research

- Manuscript accessibility in different formats

( Pdf, E-pub, Full Text, Audio)

- Unceasing customer service

Track the below URL for one-step submission https://juniperpublishers.com/online-submission.php 